\title{
Research
}

\section{Institutional Barriers to Climate Change Adaptation in U.S. National Parks and Forests}

\author{
$\underline{\text { Lesley C. Jantarasami }}^{1}, \underline{\text { Joshua J. Lawler }}^{1}$, and $\underline{\text { Craig W. Thomas }}^{1}$
}

\begin{abstract}
Climate change will increasingly challenge ecosystem managers' ability to protect species diversity and maintain ecosystem function. In response, the National Park Service and the United States Forest Service have promoted climate change adaptation as a management strategy to increase ecosystem resilience to changing climatic conditions. However, very few examples of completed adaptation plans or projects exist. Here, we examine managers' perceptions of internal and external institutional barriers to implementing adaptation strategies. We conducted semi-structured interviews $(n=32)$ with regional managers and agency staff in six park and forest units in Washington State. We found that internal barriers, including unclear mandates from superiors and bureaucratic rules and procedures, are perceived as greater constraints than external barriers related to existing federal environmental laws. Respondents perceived process-oriented environmental laws, such as the National Environmental Policy Act, as enablers of adaptation strategies, and prescriptive laws, such as the Endangered Species Act, as barriers. Our results suggest that climate change adaptation is more often discussed than pursued, and that institutional barriers within agencies limit what can be accomplished.
\end{abstract}

Key Words: adaptation; climate change; ecosystem management; institutional barriers

\section{INTRODUCTION}

The Earth's climate has changed significantly over the last 100 years and is projected to change even more in the coming century. Global average annual temperatures have risen $0.83^{\circ} \mathrm{C}\left(1.5^{\circ} \mathrm{F}\right)$ since 1900 , with much of that warming occurring over the past 30 years (Karl et al. 2009). By the end of the century, the average annual temperatures in the United States are projected to increase by 3.8 to $6.1^{\circ} \mathrm{C}$ (7 to $11^{\circ}$ $\mathrm{F})$ if current growth in greenhouse gas emissions continues (Karl et al. 2009). On average, precipitation in the U.S. has increased by roughly 5 percent over the past 50 years and the amount, intensity, frequency, type, and seasonal timing of precipitation is projected to change further in the coming century (Karl et al. 2009). In many regions of the U.S., precipitation is projected to increase in fall and winter with more falling as rain rather than snow, and decrease in summer, likely exacerbating areas already affected by seasonal drought (Karl et al. 2009).

\footnotetext{
${ }^{1}$ University of Washington
}

These climatic changes have in some cases led to, and will likely lead to additional, sea level rise, reductions in in-stream flows and water quality, increases in the frequency and intensity of heavy rains and flooding, increases in the frequency and extent of forest fires and insect outbreaks, and reduced snowpack, glaciers, permafrost, and sea ice (Intergovernmental Panel on Climate Change 2007, U.S. Climate Change Science Program 2008, Karl et al. 2009). All of these changes will affect ecological systems. The latest assessment reports from the Intergovernmental Panel on Climate Change (IPCC) and the U.S Global Change Research Program (USGCRP) indicate that even if substantial reductions in greenhouse gases occur now, changes in climate are already underway at a rate that may threaten the ability of certain species and ecological processes to persist in the future (IPCC 2007, Karl et al. 2009).

Given these circumstances, scientists, natural resource managers, and policy makers are increasingly advocating adaptation, in addition to 
mitigation, as a means of sustaining natural systems (Heller and Zavalata 2009, Climate Adaptation Knowledge Exchange 2010, Council on Environmental Quality 2010). In contrast to mitigation, which seeks to reduce emissions of greenhouse gases affecting the climate system, adaptation aims to prepare for and respond to changes that have already occurred and will occur regardless of how aggressively emissions are reduced. The USGCRP defines adaptation as management strategies aimed at reducing adverse risks to ecological systems by increasing their resilience to climate change stressors (U.S. Climate Change Science Program 2008). Many broad adaptation strategies have their roots in traditional conservation and ecosystem management principles. These include reducing existing stressors such as pollution, invasive species, and habitat fragmentation; managing for ecosystem processes and function rather than for particular species or community types; and establishing habitat buffers and wildlife corridors to connect existing protected habitat with potential future suitable habitat (U.S. Climate Change Science Program 2008, Heller and Zavaleta 2009). Some of the more controversial adaptation strategies that have been proposed include species "triage", that is, concentrating conservation efforts on the species with the greatest chance of survival, and translocation of threatened species to new environments where they did not previously exist (Heller and Zavaleta 2009).

The concept of managed adaptation to climate change has been circulating in academic and international policy arenas since the first IPCC assessment report in the early 1990s. However, it has only recently become prominent in the domestic policy discourse of U.S. federal land management agencies. The Department of Agriculture's U.S. Forest Service (USFS) formally adopted a policy framework document in late 2008 that identified adaptation as a key agency goal and recommended integrating climate change considerations into agency-wide policies and program guidance. The Department of Interior issued a series of policy documents in 2009 asking the National Park Service (NPS) and other agencies within the Department to initiate both adaptation- and mitigation-focused actions to address current and future impacts of climate change. Despite this emerging focus at the national level, very few examples of completed plans or fully implemented adaptation projects exist at the individual unit level, such as the National Park, National Forest, or National Wildlife Refuge
(U.S. Climate Change Science Program 2008, Heller and Zavaleta 2009).

To understand why so few plans and projects for climate change adaptation exist in practice, our research examined the perceptions of agency staff and managers regarding institutional barriers in individual units of the two largest federal land holders in Washington State, namely the NPS and the USFS. We examined both internal and external barriers. Internally, we examined the extent to which agency staff and managers believed they had a mandate from their superiors to implement climate change adaptation projects, and what types of internal changes they believed were needed to implement adaptation plans and projects. Externally, we examined their perceptions of how existing federal environmental laws hinder or enable adaptation.

Institutional rules and norms can serve either as barriers to, or enablers of, action within public agencies. Formal institutions are rules that "forbid, permit or require some action or outcome" (Ostrom 1990:51). Informal institutions are cultural norms and shared understandings about appropriate behavior (DiMaggio and Powell 1991). All public agencies are institutions, but they vary in the extent to which they have been institutionalized, that is, the extent to which they are governed by rules and/ or professional norms that enable or hinder individual behavior (March and Olsen 1989). Highly institutionalized agencies, such as the USFS and NPS, resist change because the rules and norms governing individual behavior serve to maintain the status quo (Kaufman 1960, Thomas 2003). In such agencies, policy directives that merely enable staff to pursue certain activities, such as climate change adaptation plans and projects, may not encourage staff to do so because these activities are not required by rules, and may not be understood as a priority by norms.

The environmental management literature identifies a number of institutional barriers to policy implementation that may explain the lack of new, on-the-ground, adaptation projects in the NPS and USFS. Barriers related to legislation include potential conflicts between current legal requirements and the new management approaches recommended for adaptation, which may limit management options (Luers and Moser 2006, U.S. Climate Change Science Program 2008). Barriers related to organizational procedures and policies include short 
planning horizons; reliance on historical trends to drive management decisions; difficulty planning given the uncertainty of local climate impacts; difficulty envisioning desired future conditions in a changing climate; and lack of clarity regarding how to address climate change at different organizational scales (Luers and Moser 2006, University of Washington Climate Impacts Group 2007, U.S. Climate Change Science Program 2008). Moreover, the adaptation literature suggests that perceptions of barriers can limit action just as strongly as actual barriers, even when the capacity and resources to adapt exist (Adger et al. 2007). In this paper, we focus specifically on perceptions of barriers.

\section{METHODS}

\section{Study areas}

The six individual units we examined are located in Washington State: Mt. Rainier National Park, North Cascades National Park, Olympic National Park, Mt. Baker-Snoqualmie National Forest, OkanoganWenatchee National Forest, and Olympic National Forest. All three parks are within the NPS Pacific West Region and all three forests are within the USFS Pacific Northwest Region. These two regional offices are leaders on climate change issues because they were among the first regions in the USFS and NPS to direct individual units to consider opportunities for climate change adaptation in their work. We then paired individual NPS and USFS units based on adjacent land ownership (Fig. 1). For example, Olympic National Park was paired with Olympic National Forest. Comparing individual units across agencies allowed us to hold other factors relatively constant, such as the types of environmental change occurring on the ground, the types of scientific and policy information available to managers, directives from the regional offices, and socioeconomic factors that might affect planning and implementation processes. Factors that may vary across the three pairings include different types of climate change impacts most likely to occur in the future, such as fire vs. flooding, local vulnerability to impacts given current ecological conditions and managers' capacity to respond, and managers' prior experience planning and managing for relevant impacts. We expected that the perceptions of participants within each agency would be fairly consistent across different units, but that their perceptions would vary across different hierarchical levels within each agency.

\section{Interviews and data analysis}

We used a purposive sampling technique that targeted managers and resource specialists based on their job title and position within each NPS and USFS unit. We intentionally sought a range of subjects with differing primary duties, responsibilities, and decision making authority to obtain a crosssection of perceptions about climate change adaptation at different levels within each unit. We also conducted interviews with the NPS Regional Director and the USFS Deputy Regional Forester, both of whom had line-management authority over the individual units in their respective agencies. In total, we conducted 32 interviews with two regional managers, six unit managers (either the Park Superintendent or Forest Supervisor/Deputy Forest Supervisor), six heads of the natural resources division, six heads of the environmental compliance and planning divisions, and 12 natural resource specialists, whose specialties ranged from wildlife biologists to hydrologists to fire ecologists. In two cases, deputies (i.e., second in command) represented the Regional Director and Forest Supervisor in the interview, but these positions are comparable with their counterparts in the NPS.

The majority of interviews $(n=27)$ were conducted in person; the remaining were conducted via video teleconference $(n=3)$ or phone $(n=2)$ due to extenuating circumstances that prevented an inperson meeting. All interviews were conducted between January and April 2009 and were voice recorded with the respondents' consent. The interviews were conducted using a 10-question interview guide, with five questions serving as the focus of this paper (see footnotes in Table 1). The interview guide allowed us to maintain consistency in data collection for comparative purposes, while the open-ended questions allowed flexibility for respondents to address themes and topics they deemed important.

Interview data were transcribed and analyzed using an inductive coding method, which involved systematically organizing and analyzing segments of text to identify patterns and themes in interviewee responses (Marshall and Rossman 1999). With inductive coding, codes are developed during the analysis process as patterns and themes emerge in the data. We describe in Table 1 and in the Results section how we coded interviewee responses for the five questions that are the focus of this paper. Coding error is necessarily present in qualitative 
Fig. 1. Geographic location of case study sites. This map was created from Washington State Department of Ecology and Department of Transportation Geographic Information Systems data (Washington State Department of Transportation 1994, Washington State Department of Transportation 1999a, Washington State Department of Transportation 1999b).

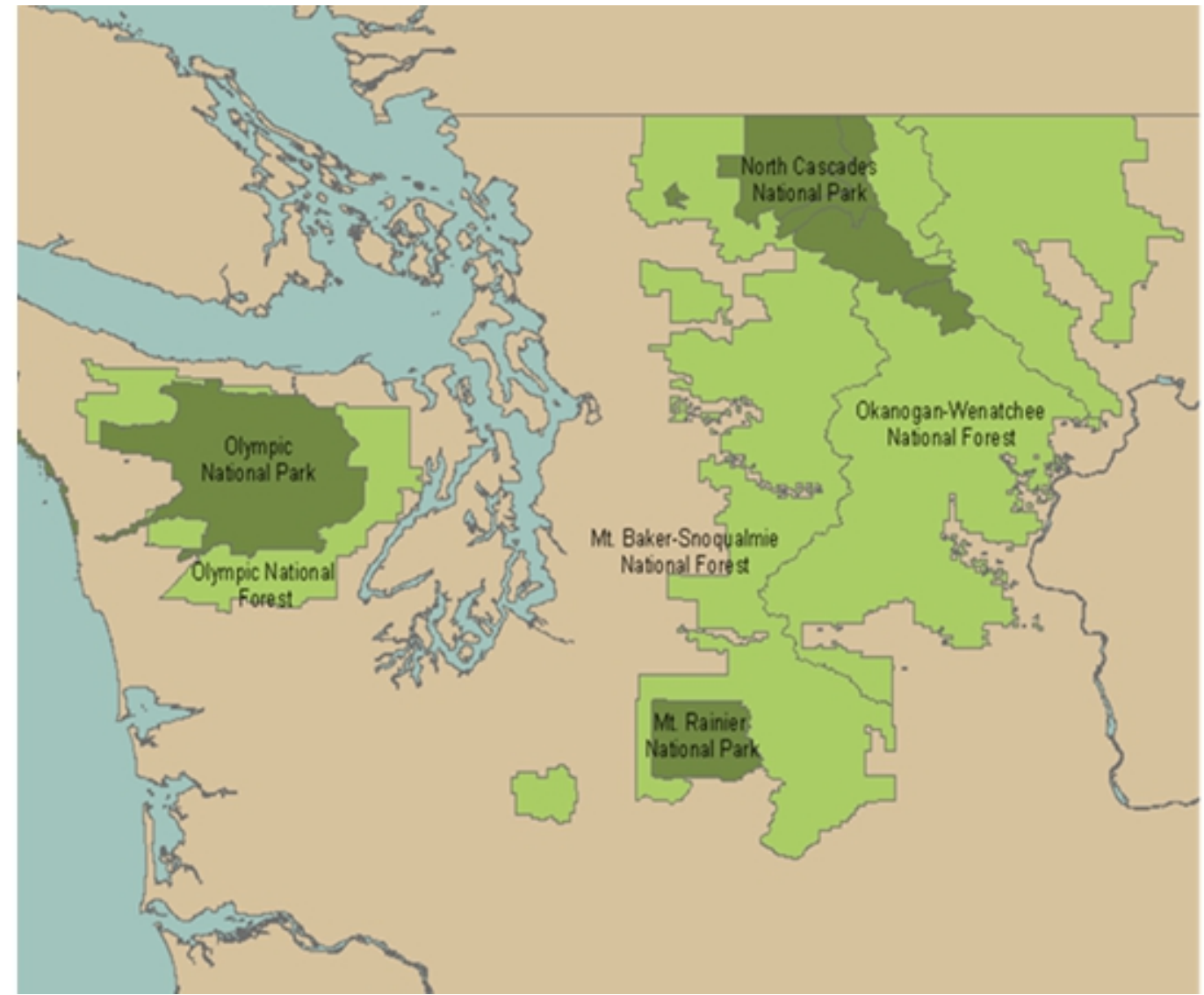

data analysis to some extent; however, where responses to interview questions had less than $100 \%$ agreement, it is more likely that this reflects differences in the subjective impressions of the interview subjects rather than coding error. We used only one data coder; therefore, we did not perform an inter-coder reliability test.

Given that non-random sampling techniques were used to select both the case studies (individual units) and the interview subjects (managers and staff), caution must be exercised in generalizing to other units, regional offices, or agencies. We justify the non-random sampling in two ways, one at the regional level and the other at the individual level.
At the regional level, the USFS and NPS regional offices overseeing the units in Washington State were among the first to direct their units to consider adaptation opportunities. Hence, the units within these regions are good test cases of the upper bound of climate change adaptation projects in these agencies nationwide. At the individual level, nonrandom sampling was necessary given the small number of people occupying relevant positions in the agencies, and the benefits accrued from matching positions across units and agencies to compare the perceptions of managers and staff regarding barriers to, and enablers of, climate change adaptation. 


\title{
Table 1. Interview guide questions.
}

\author{
Interview Guide
}

1. What do you do in your job related to climate change?

2. Are people participating in climate change adaptation discussions in your agency?

3. Is your unit considering implementing climate change adaptation strategies? ${ }^{\dagger}$

Responses were coded twice, first according to whether the adaptation example identified addressed infrastructure or forest health concerns and secondly according to whether the example was a one-time project or part of a long-range plan. The five codes used were:

-Infrastructure, Project

-Infrastructure, Long-range

-Forest Health, Project

-Forest Health, Long-range

- None

4. Is there a policy mandate to implement climate change adaptation strategies in your unit?

Responses were coded twice, first according to whether the respondent believed a mandate existed either at the agency-wide or regional level. Secondly, responses were coded according to the respondents' perceptions of whether or not the agency provided clear guidance for how to implement the mandate.

The six codes used were:

-Agency Mandate; Clear Implementation

-Agency Mandate; Unclear Implementation

-Regional Mandate; Clear Implementation

-Regional Mandate; Unclear Implementation

-No Mandate

-Other

5. What are some roadblocks or barriers to implementing adaptation strategies? $†$

Responses were coded according to the type of perceived barrier identified. The eight codes used were:

-Lack of Information

-Lack of Resources

-Potential Public Opposition

-Internal Inertia to Change

-Partners' Inertia to Change

-Internal Operating Procedures

-External Environmental Laws

-Ownership Mosaic

6. To what extent do current environmental laws allow you to plan for and implement adaptive strategies?

Responses were coded twice, first according to the law identified and secondly according to whether that law or policy was perceived as an enabler of or a barrier to climate change adaptation. The laws discussed were:

-Clean Air Act

-Clean Water Act

-Endangered Species Act

-Emergency Relief for Federally-Owned Roads

-National Environmental Policy Act

-National Historic Preservation Act

-National Forest Management Act

7. Which is the most important law that influences your decision making or your work related to climate change adaptation?

8. Do these barriers to implementing adaptation strategies differ among programs that manage endangered species, forests, or water resources?

9. What would it take to move forward in the face of these barriers?

Responses were coded according to the types of actions perceived as necessary for moving forward with adaptation. The 10 codes used were:

-Update Internal Policies

-Update Partner Policies

-Change Laws

-Public Education and Dialogue

-Working Across Jurisdictions

-Monitoring \& Adaptive Management

-Information

-Funding

-Time

-Judicious Approach

10. How would you go about implementing adaptation strategies in your unit?

These questions form the focus of this paper and include descriptions of how the responses were coded. 


\section{RESULTS}

\section{Current adaptation projects in the NPS and USFS units}

We asked interview participants if their individual unit had considered implementing climate change adaptation strategies. Participants from all three USFS units identified a total of five projects that in some way considered the potential future impacts of climate change, while two NPS units, all except Olympic National Park, identified three projects. Adaptation was a major consideration for some projects, while for others it was simply an additional criterion to consider during the planning process. For example, respondents in both agencies noted that their units were in the process of assessing infrastructure adaptation options such as relocating, upgrading, or decommissioning roads in areas that have experienced more frequent and severe floods, and that are likely to continue to do so under future climate change. For these projects, climate change was a major consideration. By contrast, respondents in one National Forest identified forest thinning plans that used climate change adaptation as an additional justification for thinning to increase ageclass and structural diversity in the forest, which would promote resilience to future stress under climate change. In this example, adaptation was simply an additional criterion considered for plans that would move forward regardless of climate considerations.

\section{Internal policy mandates as enablers of adaptation}

We asked participants if their agency had a policy mandate, that is, a written policy direction from upper management, to implement climate change adaptation plans and projects. Formal policy mandates are institutional rules that forbid, permit, or require particular actions. Participants described their perceptions of whether or not a mandate existed at the agency-wide or regional level, and also whether or not the mandate provided clear or explicit guidance for implementation. Responses between the two agencies were divided in this regard (Fig. 2). NPS respondents were unanimous in responding that their agency did not have a climate change adaptation mandate at the national level. At the regional level, however, some respondents (44\%) said there was policy direction from the NPS Pacific West Regional Office for all new general management plans to consider potential climate change impacts, but there was no specific implementation guidance. Hence, the regional-level policy mandate in the NPS required only that new plans consider climate change; it did not mandate specific actions, and respondents did not believe they were explicitly required to begin planning or implementing adaptation. A majority of respondents (56\%), particularly those at the lower levels of the NPS hierarchy, were unaware of the regional mandate.

The USFS respondents differed in their responses. Whereas no NPS respondents were aware of a policy mandate from their national headquarters, all USFS respondents (100\%) indicated that they were aware of official policy statements from their national headquarters office calling for climate change to be considered in project and long-range planning. Yet most respondents (69\%) from across agency hierarchical levels, but particularly at the lower levels, stated that these directives were unclear because they lacked specific guidance about implementing actions at the unit level. Far fewer (31\%), but more from upper management, reported that they had explicit implementation guidance at the unit level.

\section{Multiple barriers to implementing adaptation}

The perceived barriers to implementing adaptation that respondents identified fell within eight categories (Fig. 3). Notably, there was little variance in responses between units and between levels within an agency's hierarchy. The first three categories, which are lack of information, lack of resources, and perceived public opposition, represent input constraints. That is, adaptation projects are hindered by insufficient climate change impacts information at a scale relevant to regionallevel or local-level management; insufficient financial and staff resources; and concern about insufficient support from stakeholder groups who might oppose adaptation projects, which could lead to administrative appeals or lawsuits.

In addition to input barriers, respondents also identified five categories of institutional barriers. With regard to informal barriers, a minority of respondents (38\%) from both agencies discussed internal inertia to changing traditional ways of thinking about conservation and resource management that were embedded within the 
Fig. 2. Interviewee responses regarding internal agency mandate to implement adaptation.

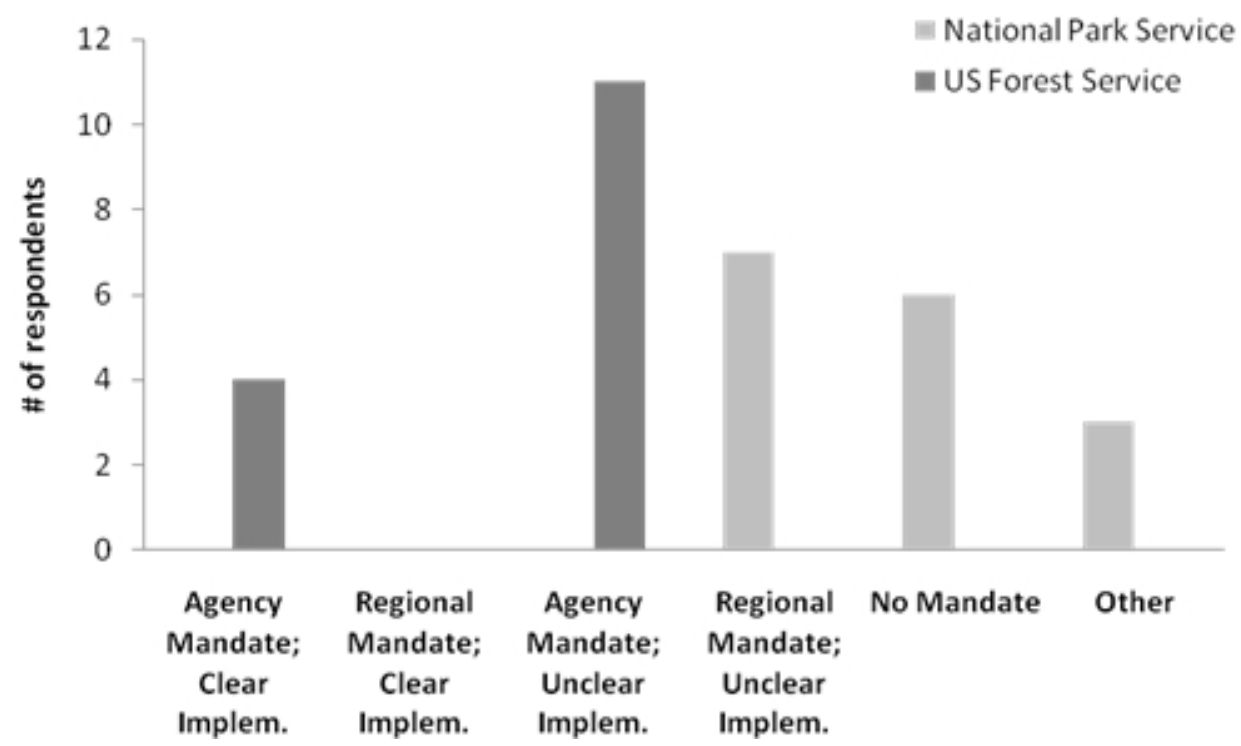

Note: Responses were coded into one of six categories, with no overlap between NPS and USFS responses within categories. Agency Mandate; Clear Implementation indicates that respondents believed there was an agency-wide policy mandate that clearly communicated how to implement actions at the individual unit level. Regional Mandate; Clear Implementation indicates that respondents believed there was a regional-level policy mandate that clearly communicated how to implement actions at the individual unit level. Agency Mandate; Unclear Implementation indicates that respondents believed an agency-wide mandate existed, but that it lacked specific policy guidance on what should be implemented at the unit level. Regional Mandate; Clear Implementation indicates that respondents believed a regional-level mandate existed, but that it lacked specific policy guidance on what should be implemented at the unit level. No Mandate indicates respondents believed they had no agency mandate to implement adaptation. Other indicates respondents that either did not know if there was a mandate, or chose to interpret legislation unrelated to climate change as a broad mandate to protect natural resources, including from the impacts of climate change.

agencies' professional cultures. For example, a USFS participant stated, "I think the greatest barrier is that we have a culture of thinking about the forest as a fixed entity - not thinking about change very well" (personal communication). A few respondents $(16 \%)$, mostly at lower levels of both agencies, described barriers related to the same types of inertia to change, but within partner agencies with which they must work closely to implement projects, such as the U.S. Fish and Wildlife Service.

Almost half of respondents $(47 \%)$ from both agencies perceived internal operating procedures to be formal barriers. For example, a NPS respondent stated, "We're going to [have to] look at how we can accommodate adaptive strategies with [internal] policies that, by [and] large, are written fairly clearly [and that indicate] that we generally don't engage in adaptive strategies in terms of moving populations or reintroducing populations of plants or animals, for example, or taking extraordinary action to preserve something that's unique and special in a particular location. Manipulating the environment, you know" (personal communication). Some respondents $(38 \%)$ also perceived that external environmental laws acted as barriers, although when asked in more detail about how laws affect their ability to implement adaptation, overall 
Fig. 3. Interviewee responses regarding barriers to implementing adaptation.

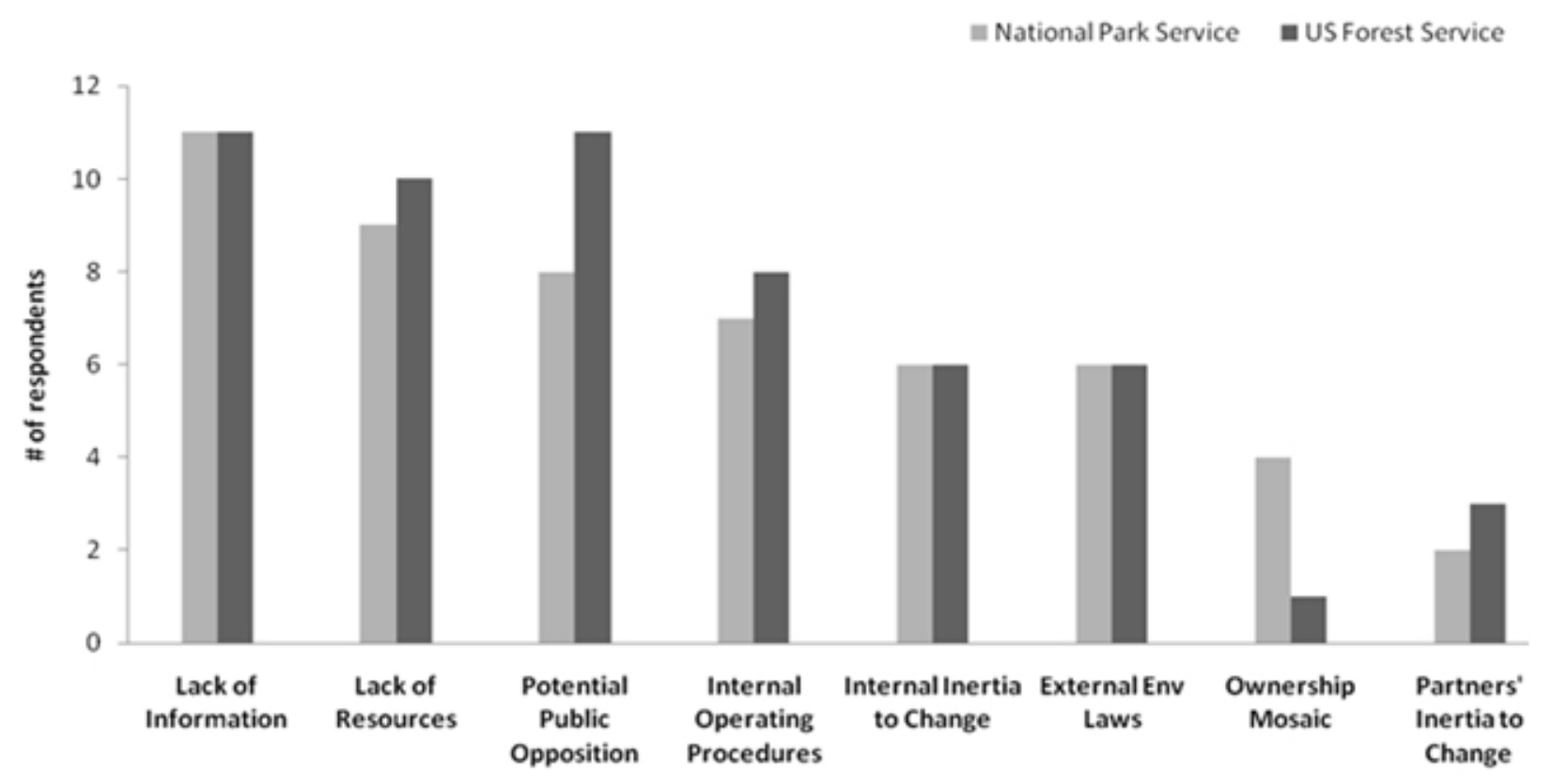

Note: Responses were coded according to type of perceived barrier described. Input barriers included Lack of Information, i.e., insufficient data to predict likely climate impacts at the individual unit level and then translate that information into an adaptation strategy; Lack of Resources, i.e., insufficient budget and staff time to plan for and implement adaptation in addition to current workload; and Potential Public Opposition, i.e., insufficient public and stakeholder support to implement adaptation. Informal institutional barriers included Internal Inertia to Change and Partners' Inertia to Change, which refers to difficulty changing traditional ways of thinking about resource management, within both the agencies themselves and their partner agencies. Formal institutional barriers included Internal Operating Procedures, i.e., agencies' formal rules and decision making processes; External Environmental Laws, i. e., existing legal constraints; and Ownership Mosaic, i.e., ecosystem boundaries span multiple jurisdictions with different rules and management objectives.

responses described laws as both barriers to and enablers of adaptation. A few respondents (16\%), primarily from one NPS unit (North Cascades National Park), but representing all levels of the agency hierarchy, perceived ownership mosaics to be formal institutional barriers given that different jurisdictions operate under different rules.

\section{External environmental laws as barriers and enablers of adaptation}

We asked participants about the extent to which environmental laws allowed climate change adaptation planning and project implementation.
Respondents were encouraged to discuss whichever laws they deemed important. In total, participants identified nine laws and described their perception of how the laws enabled or impeded their ability to implement climate change adaptation (Fig. 4a and 4b). Notably, there was little variance in responses between units and between levels within an agency's hierarchy. We coded laws as enablers when participants described a law as, at a minimum, not hindering their ability to plan for and implement adaptation, or at best, as helpful in incorporating climate change considerations into management decisions. Responses were classified as barriers when participants described the laws as reducing their flexibility to implement adaptation according 
to their unit's needs and circumstances. Because each law was not necessarily discussed by each respondent, the breakdown of responses coded as enablers and barriers does not always total $100 \%$.

Many respondents from both agencies (60\%) believed the National Environmental Policy Act (NEPA) had the potential to enable adaptation, while few $(6 \%)$ described this law as a barrier. By contrast, a large majority $(81 \%)$ of respondents believed that the Endangered Species Act (ESA) was a barrier to climate change adaptation, while few $(9 \%)$ believed this law to be an enabler. Many respondents also viewed the NPS Organic Act $50 \%$ of NPS respondents) and the Wilderness Act (41\% of all respondents) as potential barriers to adaptation. One quarter of all USFS respondents described the National Forest Management Act (NFMA) as enabling adaptation, while another quarter perceived it as a barrier.

A few respondents (13\%) described the Emergency Relief for Federally-Owned Roads program of the Federal Highways Administration as a current barrier to adaptation. This program, which is authorized under Title 23, United States Code Section 125(e), provides funding and engineering services to repair and restore federally-owned roads damaged by natural disasters or catastrophic failures. Although the roads program is not an environmental law, respondents considered it to be an important aspect of the natural resource management policy context.

\section{Means for overcoming institutional barriers to adaptation}

Participants were asked what it would take to move forward in the face of the barriers they identified. The results show a wide range of ideas for overcoming barriers to adaptation (Fig. 5), with notable similarities in responses between units and between levels within an agency's hierarchy. Surprisingly, although a number of laws were identified as potentially hindering adaptation, only five participants from each agency (31\% of total participants) saw a need for Congress to change the laws. Some respondents stated concerns that the process of amending laws is so political that they might end up with something even more restrictive than what they had before. Instead, 11 NPS respondents and 15 USFS respondents (81\% of total) stated that internal policy mandates and formal agency rules regarding implementation of environmental laws needed to be changed to become more dynamic, flexible, and accommodating of adaptation. They believed that the laws were probably flexible enough to begin implementing adaptation in most circumstances. A response unique to some NPS participants (31\%) was concern about the agency changing its internal policies on minimal intervention too hastily. They believe that the NPS should proceed carefully and ensure solid scientific justification for all potential adaptation projects. Few respondents in either agency mentioned overcoming input barriers as a priority (Information: 25\%, Funding: 25\%, Time: 12.5\%). This could be due to the fact that these units are in the initial stages of planning for adaptation and are not yet thinking about the more routine aspects of project implementation.

\section{DISCUSSION}

\section{Effect of external laws on implementing adaptation}

We found unexpected nuances and consistency in our results regarding the possible effects of existing federal environmental laws on adaptation to climate change. Although respondents were only asked to characterize laws as "barriers" or "not barriers", their responses were more nuanced and indicated that some laws may actually enable implementation of climate change adaptation. Our results also show surprisingly widespread agreement between and within NPS and USFS units and across agency hierarchical levels. Respondents generally believed that NEPA can aid adaptation while the ESA may hinder adaptation. Respondents believed NEPA would not likely hinder climate change adaptation because it is a procedural law that requires analyzing and disclosing the effects of proposed actions, but cannot prevent an action from moving forward. In addition, NEPA has a high potential to enable adaptation because it provides an established process for analyzing different management alternatives, which may assist staff in incorporating climate change considerations into their planning. But NEPA is a two-edged sword in this regard, given that opponents of a project can similarly use NEPA's extensive legal procedures to delay or prevent project implementation (Karkkainen 2002, MacGregor and Seesholtz 2008). For example, a USFS study found that excessive NEPA appeals and litigation have required the agency to expend considerable 
Fig. 4. NPS and USFS interviewee responses regarding effect of key federal laws on adaptation.
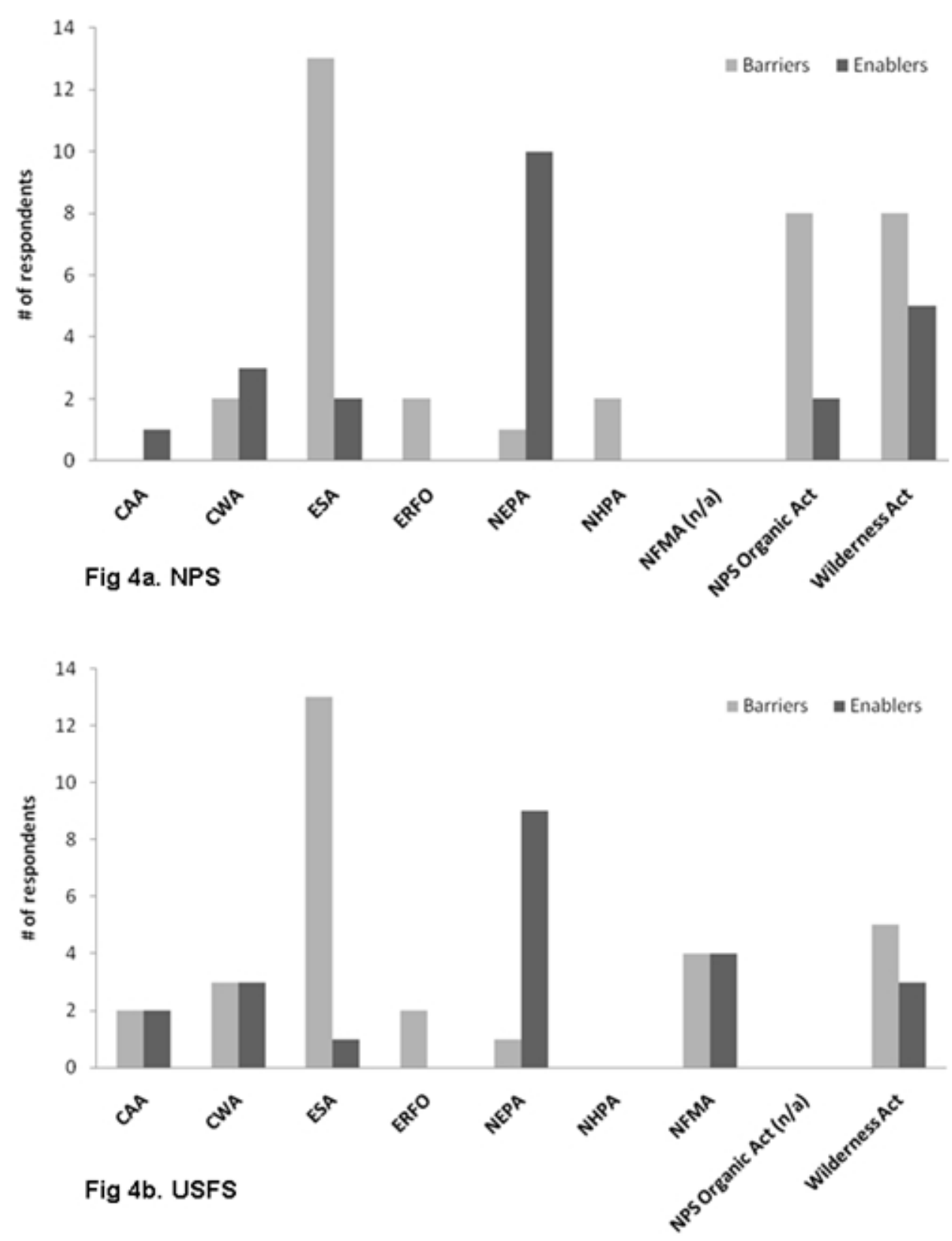

Note: The top graph (Fig. 4a) is for NPS respondents and the bottom (Fig. 4b) is for USFS respondents. Responses were coded according to environmental laws mentioned. The gray bars indicate laws that were perceived as barriers to implementing adaptation, while the black bars indicate laws perceived as enabling adaptation. There are no NPS responses for the NFMA because it applies only to the USFS. Similarly, there are no USFS responses for the NPS Organic Act because it applies only to the NPS.

Key: CAA-Clean Air Act; CWA-Clean Water Act; ESA-Endangered Species Act; ERFO-Emergency Relief for Federally-Owned Roads Program; NEPA-National Environmental Policy Act; NHPANational Historic Preservation Act; NFMA-National Forest Management Act. 
Fig. 5. Interviewee responses regarding overcoming barriers to implementation.

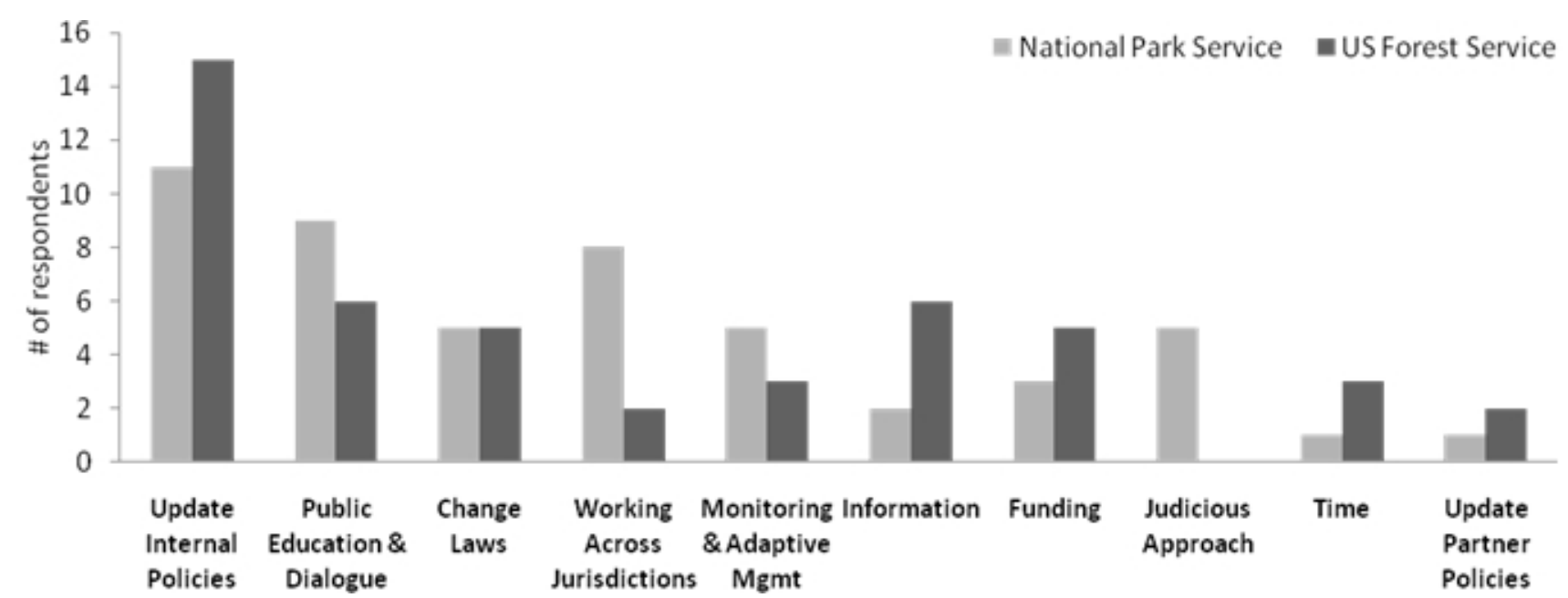

Note: Responses were coded into 10 categories. Update Internal Policies indicates a perceived need for more internal agency guidance, policy change, or a new management paradigm to support adaptation. Public Education and Dialogue indicates a perceived need to engage the public and cultivate public support for adaptation. Change Laws indicates a perceived need for Congress to modify an existing law, or pass a new law to provide more policy direction for adaptation. Working Across Jurisdictions indicates a perceived need to work with partner agencies across jurisdictions and manage at a broader spatial scale. Monitoring and Adaptive Management indicates a perceived need for utilizing these methods to understand how natural resources are changing and may be affected by climate change. Information (e.g., predictive models), Funding and Time indicate a perceived need for these types of resources in order to implement more climate change adaptation projects in the future. Judicious Approach indicates a perceived need to ensure any policy changes are well thought out and based on sound science. Update Partner Polices indicates a perceived need to change federal partners' traditional management approaches and policies to be more supportive of adaptation.

time and expense trying to "bullet-proof" project plans through extensive analysis and documentation, even for small projects (United States Forest Service 2002). Hence, NEPA may become a barrier in the future, even though the respondents perceived it to be a potential enabler.

Respondents described a high potential for the ESA to hinder adaptation given its focus on singlespecies management to recover threatened or endangered species in specific habitats and geographic areas. They believed that this approach contradicts adaptation's emphasis on dynamic management of ecosystem processes and recognition that it may not be possible to sustain all species in their current ranges under a changing climate. Respondents also noted tensions between short- and long-term species protection and limited ability to actively manage in areas designated as critical habitat or containing nesting sites. For example, respondents in the Okanogan-Wenatchee National Forest identified a potential conflict with forest thinning restrictions in Northern Spotted Owl (Strix occidentalis caurina) critical habitat. While nesting sites may be protected in the short-term, they may face long-term risks given the projected increase in frequency and severity of fire east of the Cascade Mountains due to climate change. In all three National Parks, one or more respondents identified examples of road repair or relocation projects made necessary by an increased frequency and severity of flooding linked to climate change. The projects may adversely affect designated critical habitat of threatened species like the 
Northern Spotted Owl and Bull Trout (Salvelinus confluentus), and participants expressed concern about the prospect of facing difficult tradeoffs in the future, such as being forced to choose between protecting endangered species and protecting or restoring important ecosystem processes like river channel migration.

Respondents also believed the NPS Organic Act and the Wilderness Act had high potential to hinder adaptation. These laws emphasize preservation and naturalness and have led to agency policies of minimal intervention and management in wilderness areas and in National Parks. These hands-off types of policies are perceived as potential barriers to implementing certain proposed adaptation strategies that require extensive management intervention and manipulation to achieve adaptation goals. In particular, respondents noted that the Wilderness Act's prohibition against infrastructure development and use of mechanized equipment in designated wilderness areas, which can comprise millions of acres of a National Park or Forest, may preclude certain types of adaptation projects. Examples discussed included situations where, without heavy moving equipment, stream channels destroyed by floods could not be properly restored, and where roads continually washed out by recurring floods could not be relocated because they are bordered on both sides by a wilderness area.

Respondents believed that the emergency roads program had the potential to enable road infrastructure adaptation by providing funding for projects to address recurring flood damage to roads such as through road relocation and culvert upsizing. However, participants indicated that the program is currently a hindrance because the Federal Highways Administration generally only authorizes replacement of damaged roads in the original locations and is reluctant to approve projects to upgrade roads in anticipation of increased future flooding due to climate change. Respondents regarded the program's short-term approach to replacing roads in the same location, rather than relocating them to more stable areas, as a lost opportunity to take action to adapt to the likelihood of more frequent and larger floods resulting from climate change. They noted that the program could become more supportive of adaptation if the Federal Highways Administration changed its internal policy to allow more funding for road relocation.
One quarter of USFS respondents believed NFMA could enable implementation because it provides a structure and process for long-range strategic planning, while another quarter believed it has the potential to hinder implementation of climate change adaptation strategies because Forest Plans could not be revised quickly or easily to incorporate new, relevant scientific findings related to climate change and likely impacts on natural resources.

The hindering and enabling characteristics of current environmental laws will become more evident as ecosystem managers implement adaptation more extensively. At the time of our interviews, individual units were still in the initial planning stages and respondents did not report any examples of completed adaptation projects, so their responses reflect future expectations rather than direct experience with implementation. Because the NPS and USFS were still in the early stages of planning for adaptation, other factors may become more or less relevant as they begin on-the-ground implementation. For example, the transjurisdictional barriers identified in Fig. 3, namely "ownership mosaic" and "partners' inertia to change", would likely be cited by a larger number of respondents if planning and projects were further along (Thomas 2003). Further, managers and staff would likely have had more variable responses if adaptation plans and projects had been more advanced, as their distinct organizational roles and responsibilities shape their perspectives on implementation and their perceptions of relevant barriers or enablers.

The interview results suggest that the perceived major barriers to getting adaptation projects off the ground are more related to internal organizational processes than legislative barriers. Although certain laws were viewed as barriers, most agency employees prefer the certainty of dealing with existing laws rather than changing them in response to climate change. Results show a strong preference to work within the existing legal structure but update internal operating procedures to enable more flexible management.

\section{Internal policy guidance and support for implementation}

Within the USFS, respondents indicated an overall awareness of the importance of climate change adaptation in their agency, although the majority $(69 \%)$ believed that the policy mandate they had 
received was unclear with regard to implementation. In other words, there were formal institutional rules within the USFS that permitted managers and staff to address climate change as an issue of concern, but there were no rules requiring climate change adaptation projects. In contrast, NPS respondents unanimously reported that they did not have an agency-wide policy mandate that clearly communicates that adaptation is a priority to all levels of the agency, nor had they received substantive direction and a framework for implementing actions at the individual unit level. Respondents in both agencies indicated they were unsure of what specific actions they should implement and what, if anything, they should be doing differently in their jobs to respond to climate change. This is consistent with the findings of a 2007 Government Accountability Office report, which concluded that "resource managers have limited guidance about whether or how to address climate change and, therefore, are uncertain about what actions, if any, they should take" (Government Accountability Office 2007:1).

The limited number and scope of examples of adaptation in the individual units studied here also suggest that climate change adaptation has not yet been integrated into managers' current job responsibilities; it was an additional, rather than essential, part of their work. To the extent that the six case study units had addressed climate change adaptation at all, they took a limited approach in the absence of more specific agency guidance. Individual units considered adaptation only in terms of infrastructure protection and forest health, and even then only when it was consistent with existing agency policy and procedures. Furthermore, the results illustrate reactive rather than anticipatory adaptation (Repetto 2008, U.S. Climate Change Science Program 2008); individual units were assessing potential infrastructure adaptation options only in areas that have already experienced more frequent and severe floods, not where future floods may occur. Repetto (2008) states that reactive adaptation by its very nature lags behind emerging climate change risks and thus will be less effective at addressing future impacts. The examples of forest health adaptation strategies in USFS units relied on traditional forest management approaches, such as mechanical thinning and prescribed burning, with the primary goal of correcting overly dense forest stands created through years of fire suppression. Climate change adaptation represented a secondary co-benefit of these projects, namely, increased resistance to, and resilience in the face of, fire, insects, and disease.
The slow adoption of climate change adaptation at the individual unit level is not surprising given that the NPS and USFS have long operated through a traditional system of hierarchical authority, welldefined job descriptions, and standard operating procedures. These bureaucratic rules make it difficult to respond quickly to changing environmental problems, external laws, and internal policy directives (Kaufman 1971, Sabatier et al. 1995). Without an explicit internal mandate and clear delegation of authority and responsibilities, unit-level managers may be unable or reluctant to devote staff time and resources to implementing significant policy changes for climate change adaptation. Moreover, these bureaucratic rules impede the ability of agency managers and staff to develop plans and projects that cross agency jurisdictions (Thomas 2003).

If unit-level managers in the future desire to plan for and implement adaptation strategies, the bureaucratic model suggests they would not likely follow through given perceptions that are outside their unit's management authorities. Instead, as our interview examples show, they would favor adaptation strategies that support existing agency policy goals ("no-regrets" strategies) and require minimal changes to current management practices. Given the bureaucratic structure and culture of the NPS and USFS, more extensive proactive adaptation strategies may not be widely implemented until upper management clearly states that adaptation is a unit-level as well as agency-wide policy priority, requires units to pursue whatever adaptation options are deemed appropriate to address local environmental conditions, and provides requisite levels of funding and staffing for implementation.

\section{CONCLUSION}

A number of general recommendations follow from this study. The results suggest that national- and regional-level agency managers should reduce formal and informal institutional barriers to adaptation by: (1) establishing a clear agency policy mandate for adaptation that requires climate change adaptation to be a primary concern, not just a supplementary criterion to be considered in planning processes; (2) educating employees about adaptation to generate internal support; (3) creating formal divisions of labor to allow staff to focus exclusively on climate change issues; and (4) providing requisite funding and staff to support 
adaptation strategies. Bureaucratically-organized agencies such as the NPS and USFS must expend considerable effort to modify their traditional decision making rules to establish more flexible management processes, and to generate internal support from all levels of the agency for these changes. In the management literature, this is known as moving from a system based on "red tape" that impedes action to one based on "green tape" that enables action (DeHart-Davis 2009). Existing research also emphasizes the importance of team work in breaking and reshaping organizational routines (Foldy and Buckley 2010).

Because the selection of appropriate adaptation strategies depends on the predicted local climate impacts and environmental conditions, there can be no one-size-fits-all agency direction as to what adaptation strategies should be implemented. Unitlevel managers are better positioned to make those decisions based on their knowledge of the local context. National-level policy makers should provide the requisite resources, including funding, staff, and information, to empower unit-level decision making and action. This could be accomplished through: (1) providing incentives that encourage local innovation, such as through internal awards competitions or showcase projects; (2) establishing a system for learning and sharing lessons from mistakes and successes at the local level, such as online newsletters, message boards, or wiki sites; (3) facilitating opportunities for interaction among ecosystem managers, maintenance and operations personnel, and scientific staff both within and across agencies; and (4) coordinating information resources across agencies and jurisdictions, for example, web portals or data clearinghouses with maps, documents, or computer models relevant to local management, such as regional climate models, hydrology, or fire risk. Efforts such as these will better inform managers and decision makers in their efforts to adapt to climate change, facilitate dynamic decision making, and assist in the continual evaluation and revision of management strategies and plans in response to changing environmental conditions.

As of 2009, staff and managers in NPS units in Washington State perceived no mandate to address climate change, while a majority in the USFS perceived a mandate but did not know how to act on it without more specific direction. The recommendations listed above suggest how institutional changes within these agencies can aid in moving climate change adaptation forward. Respondents did not perceive environmental laws as preventing action at the time, but did believe that process-oriented laws like NEPA would be more likely to enable adaptation, while prescriptive laws like ESA would more likely hinder adaptation, should these laws come into play. Unit land managers expressed the greatest need for institutional changes within their agencies to provide a clear policy mandate about what to do, which resources are available to do so, and loosened bureaucratic rules to move more quickly to plan for and implement adaptation projects.

Responses to this article can be read online at:

http://www.ecologyandsociety.org/voll5/iss4/art33/ responses/

\section{LITERATURE CITED}

Adger, W. N., S. Agrawala, M. M. Q. Mirza, C. Conde, K. O'Brien, J. Pulhin, R. Pulwarty, B. Smit, and K. Takahashi. 2007. Assessment of adaptation practices, options, constraints and capacity. Pages 717-743 in M. L. Parry, O. F. Canziani, J. P. Palutikof, P. J. van der Linden, and C. E. Hanson, editors. Climate change 2007: impacts, adaptation and vulnerability. Contribution of Working Group II to the Fourth Assessment Report of the Intergovernmental Panel on Climate Change. Intergovernmental Panel on Climate Change, Cambridge University Press, Cambridge, UK.

Climate Adaptation Knowledge Exchange (CAKE). 2010. About the Climate Adaptation Knowledge Exchange. [online] URL: http://www.c akex.org/about

Council on Environmental Quality (CEQ). 2010. Climate Change Adaptation Task Force. [online] URL: http://www.whitehouse.gov/administration/eop/ ceq/initiatives/adaptation

DeHart-Davis, L. 2009. Green tape: A theory of effective organizational rules. Journal of Public Administration Research and Theory 19:361-384.

DiMaggio, P. J., and W. W. Powell. 1991. Introduction. Pages 1-38 in W. W. Powell and P. J. DiMaggio, editors. The new institutionalism in 
organizational analysis. The University of Chicago Press, Chicago, Illinois, USA.

Foldy, E. G., and T. R. Buckley. 2010. Recreating street-level practice: the role of routines, group work, and team learning. Journal of Public Administration Research and Theory 20:23-52.

Government Accountability Office (GAO). 2007. Agencies should develop guidance for addressing the effects of climate change on federal land and water resources. Government Accountability Office, Washington, D.C., USA.

Heller, N. E., and E. S. Zavaleta. 2009. Biodiversity management in the face of climate change: a review of 22 years of recommendations. Biological Conservation 142:14-32.

Intergovernmental Panel on Climate Change (IPCC). 2007. Summary for policymakers. Pages 7-22 in M. L. Parry, O. F. Canziani, J. P. Palutikof, P. J. van der Linden, and C. E. Hanson, editors. Climate change 2007: impacts, adaptation and vulnerability. Contribution of Working Group II to the Fourth Assessment Report of the Intergovernmental Panel on Climate Change. Intergovernmental Panel on Climate Change, Cambridge University Press, Cambridge, UK.

Karkkainen, B. C. 2002. Toward a smarter NEPA: monitoring and managing government's environmental performance. Columbia Law Review 102:903-972.

Karl, T. R., J. M. Melillo, and T. C. Peterson, editors. 2009. Global climate change impacts in the United States. A State of Knowledge report from the U.S. Global Change Research Program. Cambridge University Press, Washington, D.C., USA.

Kaufman, H. 1960. The forest ranger: a study in administrative behavior. John Hopkins University Press, Baltimore, Maryland, USA.

Kaufman, H. 1971. The limits of organizational change. University of Alabama Press, Tuscaloosa, Alabama, USA.

Luers, A. L., and S. C. Moser. 2006. Preparing for the impacts of climate change in California: opportunities and constraints for adaptation. California Energy Commission Publication Number CEC-500-2005-198-SF. California Energy Commission, Sacramento, California, USA.
MacGregor, D. G., and D. N. Seesholtz. 2008. Factors influencing line officers' decisions about National Environmental Policy Act project design and development. General Technical Report PNWGTR-766. United States Department of Agriculture Forest Service, Pacific Northwest Research Station, Portland, Oregon, USA.

March, J. G., and J. P. Olsen. 1989. Rediscovering institutions: the organizational basis of politics. The Free Press, New York, New York, USA.

Marshall, C., and G. Rossman. 1999. Designing qualitative research. Third edition. Sage Publications, Thousand Oaks, California, USA.

Ostrom, E. 1990. Governing the commons: the evolution of institutions for collective action. Cambridge University Press, Cambridge, UK.

Repetto, R. 2008. The climate crisis and the adaptation myth. Working Paper 13. Yale School of Forestry \& Environmental Studies, New Haven, Connecticut, USA.

Sabatier, P. A., J. Loomis, and C. McCarthy. 1995. Hierarchical controls, professional norms, local constituencies, and budget maximization: an analysis of U.S. Forest Service planning decisions. American Journal of Political Science 39:204-242.

Thomas, C. W. 2003. Bureaucratic landscapes: interagency cooperation and the preservation of biodiversity. Massachusetts Institute of Technology Press, Cambridge, Massachusetts, USA.

United States Forest Service (USFS). 2002. The process predicament: how statutory, regulatory, and administrative factors affect national forest management. U.S. Forest Service, Washington, D. C., USA.

University of Washington Climate Impacts Group (CIG). 2007. Preparing for climate change: a guidebook for local, regional, and state governments. The Climate Impacts Group, King County, Washington, and ICLEI - Local Governments for Sustainability, Seattle, Washington, USA.

U.S. Climate Change Science Program (CCSP). 2008. Preliminary review of adaptation options for climate-sensitive ecosystems and resources. U.S. 
Climate Change Science Program and the Subcommittee on Global Change Research Synthesis and Assessment Product 4.4. U.S. Environmental Protection Agency, Washington, D. C., USA.

Washington State Department of Ecology. 1994. Washington State Base Map. [online] URL: http:// www.ecy.wa.gov/services/gis/data/polsub/wash.htm

Washington State Department of Transportation. 1999a. National Forests of Washington State, at 1:24,000. [online] URL: http://www.wsdot.wa.gov/ mapsdata/geodatacatalog/Maps/24k/DOT Cartog/federal/ natfor.htm

Washington State Department of Transportation. 1999b. National Parks of Washington State. [online] URL: http://www.wsdot.wa.gov/mapsdata/geodata catalog/Maps/24k/DOT Cartog/federal/natpark.htm 